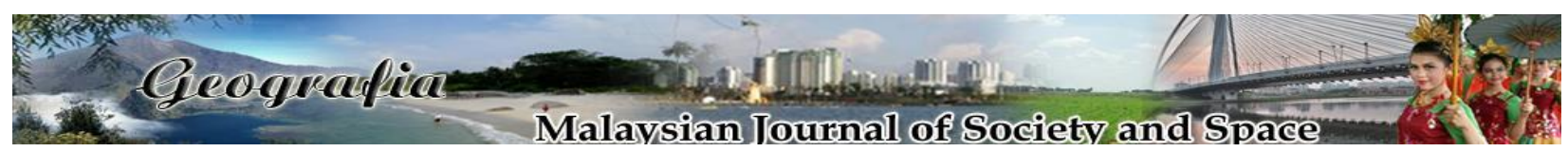

\title{
Pengetahuan pelajar dan program kitar semula di sekolah menengah Datuk Peter Mojuntin, Penampang, Sabah.
}

\author{
Chong Oi Min, Mohammad Tahir Mapa \\ Fakulti Sains Sosial dan Kemanusiaan, Universiti Malaysia Sabah \\ Correspondence: Chong Oi Min (email: oimin3344@gmail.com)
}

Received: 03 November 2020; Accepted: 22 January 2021; Published: 27 February 2021

\begin{abstract}
Abstrak
Pada masa ini, penjanaan komposisi sisa pepejal di negara kita semakin bertambah seiring dengan pertambahan jumlah penduduk. Keadaan ini menyebabkan jumlah sampah yang dihasilkan di sekolah juga meningkat. Pengetahuan dan program kitar semula perlu dilaksanakan untuk mengatasi masalah ini. Oleh itu, kajian bertujuan untuk mengenal pasti persepsi pelajar berhubung dengan pengetahuan, penglibatan dan kesedaran terhadap program kitar semula. Kajian secara tinjauan dengan menggunakan Google Form digunakan untuk mengutip data. Selain itu, kaedah kualitatif juga digunakan untuk memerhati tabiat pelajar dalam amalan kitar semula. Seramai 320 pelajar tingkatan empat dipilih secara rawak mudah sebagai responden kajian. Statistik deskriptif dengan peratusan digunakan untuk mengenal pasti tahap pengetahuan, penglibatan dan kesedaran pelajar dalam analisis ini. Dapatan menunjukkan bahawa pelajar mempunyai pengetahuan dan menyedari kepentingan program kitar semula tetapi tidak mempratikkan amalannya. Justeru, pihak sekolah harus bekerjasama dengan pihak luar untuk melaksanakan pelbagai program kitar semula agar mampu menyedarkan dan melibatkan diri pelajar. Diharapkan dengan adanya program seumpama ini dapat mengubah amalan, menarik perhatian dan minat pelajar. Sekaligus dapat mengurus sisa pepejal sekolah dengan lebih berkesan dan mendidik pelajar menjaga kebersihan alam sekitar.
\end{abstract}

Kata Kunci: Kesedaran, kitar semula, pengasingan sisa, pengetahuan, penglibatan, program kitar semula 


\title{
Student knowledge and recycling program at Datuk Peter Mojuntin Secondary School, Penampang, Sabah.
}

\begin{abstract}
In recent time, the generation of solid waste composition in our country is increasing in line with the increase in population. This scenario led to the amount of garbage generated by schools to also increase. Knowledge and recycling programs need to be implemented to overcome this problem. Therefore, the study aims to identify students' perceptions in relation to knowledge, involvement and awareness of recycling programs. Questionaire surveys using Google Forms are used to collect data. In addition, qualitative methods are also used to observe students' habits in recycling practices. A total of 320 Form Four students were randomly selected as respondents. Descriptive statistics with percentages were used to identify the level of knowledge, involvement and awareness of students in this analysis. Findings show that students have knowledge and are aware of the importance of recycling programs but do not practice it. Therefore, the school should work with external parties to implement various recycling programs in order to be able to raise awareness and to engage the students. It is hoped that the existence of such a program can change the practice, attract the attention and interest of the students. Thus enable the school to manage solid waste more effectively and educate students to maintain environmental cleanliness.
\end{abstract}

Keywords: Awareness, recycling, waste segregation, knowledge, involvement, recycling programs

\section{Pengenalan}

Dewasa ini, arus kemajuan yang berkembang pesat telah memberi banyak perubahan dan implikasi negatif kepada negara. Malaysia juga masih lagi berdepan dengan isu-isu lama seperti pembuangan sampah dan amalan 3R (Reduce, Reuse and Recycle) yang masih rendah (Seow, 2009; Agamuthu \& Tarmudi, 2012). Oleh itu, isu ini seharusnya dikendalikan oleh semua pihak di pelbagai peringkat termasuklah di peringkat institusi pendidikan. Pihak kerajaan melalui kementerian pendidikan dan sektor swasta juga telah mengadakan pelbagai program kitar semula untuk mengatasi masalah ini tetapi sehingga hari ini ia masih berlarutan tanpa penyelesaian yang sebaiknya (Hasnah et al., 2012; Murugan, 2019). Pengurusan sisa pepejal dan program kitar semula terutamanya di kalangan pelajar sekolah rendah dan menengah masih belum kelihatan amalan dan sikap mengasingkan sampah mengikut tiga warna tong sampah yang disediakan oleh pihak sekolah secara sepenuhnya (Seow, 2004; Zaini, 2011).

Lebih membimbangkan lagi, pelajar juga tidak mementingkan kebersihan dan penjagaan alam sekitar di mana mereka makan, di situlah juga mereka buang. Sebaliknya, pelajar hanya mengharapkan pekerja kontraktor di sekolah untuk membersihkannya. Kekurangan pengetahuan dan kesedaran dalam pelbagai program kitar semula di kawasan sekolah memberikan kesan negatif sedangkan sebagai pelajar sekolah seharusnya menunjukkan sikap dan teladan yang baik kepada setiap lapisan masyarakat (Siti Khatijah \& Noraziah, 2014; Hanifah et al., 2017). Majoriti pelajar membuang sampah tanpa memikirkan terlebih dahulu samada sampah itu boleh dikitar semula atau tidak. Sebaliknya menurut Rosmidzatul (2015), negara Jepun berjaya mengamalkan amalan 
kitar semula di mana $80 \%$ daripada sisa pepejal yang dibuang dijadikan bahan kitar semula manakala $20 \%$ sahaja dibuang di tapak pelupusan sampah. Situasi ini menyebabkan jangka hayat tapak pelupusan dapat dipanjangkan dan pencemaran alam sekitar juga dapat dikurangkan (Abdul Hair, 2016; Mapa et al., 2019).

Justeru itu, pendidikan alam sekitar dan program kitar semula telah diperkenalkan di Malaysia sebagai langkah jangka panjang untuk membentuk sikap positif generasi akan datang terhadap kitar semula (KPM, 2017). kesedaran menjaga alam sekitar melalui pendidikan dan kurikulum merupakan medium perubahan yang paling berpengaruh dalam kalangan pelajar sekolah. Institusi pendidikan seperti sekolah menjadi saluran utama untuk mendedahkan pendidikan kitar semula kepada sekolah dan masyarakat yang ada pada hari ini supaya pengetahuan, kemahiran dan nilai-nilai murni serta tindakan yang betul dalam menangani isu pembuangan sampah dan alam sekitar dapat dikurangkan (Murugan, 2019). Kurikulum pendidikan dan pengetahuan serta program kitar semula merupakan pengukur transformasi sikap dan tingkah laku pelajar sehingga dapat membentuk etika terhadap alam sekitar. Ramai percaya hanya melalui pendidikan sahaja, pemikiran dan tindakan seseorang pelajar dapat diubah. Jadi, sekolah adalah institusi pendidikan yang paling sesuai dan penting untuk mendidik serta membentuk amalan kitar semula di kalangan generasi akan datang agar lebih prihatin terhadap kebersihan alam sekitar kita (Seow et al., 2004).

\section{Kajian literatur}

Sisa ditakrifkan oleh Lau (2014) sebagai sesuatu bahan yang tidak diperlukan dan tidak mempunyai kepentingan dan kegunaan kepada manusia. Sisa di sekolah kebiasaanya terdiri daripada bahan plastik, kontena, polisterina, botol mineral, kertas, sisa alat tulis, tisu dan sebagainya. Perbadanan Pengurusan Sisa Pepejal dan Pembersihan Awam (PPSPPA) 2019 mendefinisikan sisa sebagai suatu proses untuk memastikan semua kawasan di permukaan bumi dijaga kebersihannya di samping memberikan pengurusan yang lebih sistematik mengikut akta dan peraturan yang ditetapkan. Manakala Ng (2015) mendefinisikan sisa sebagai suatu proses yang menglibatkan usaha daripada pemungutan, pengagihan, pengangkutan sehingga pelupusan di tapak pelupusan. Semua sisa yang dihasilkan di sekolah dan kawasan perumahan daerah Penampang diangkut dan dilupuskan di tapak pelupusan yang terletak di Kayu Matang, Telipok (Abdul Hair, 2016). Justeru, pengasingan sisa pepejal adalah sesuatu cara yang dilakukan di sekolah untuk menjaga kebersihan dan mengurus kitar semula dengan memastikan ia tiada bahan buangan di dalam kawasan sekolah. Menurut Seow (2009), purata penduduk negara kita menjana sisa pepejal lebih kurang 33,000 tan sisa pepejal pada setiap hari dengan anggaran sisa 12 juta tan metrik dalam masa setahun. Pengurusan sisa pepejal di sekolah haruslah bermula daripada proses kewujudan sesuatu sampah sehinggalah pemungutan sampah oleh lori sampah dari Majlis Daerah Penampang (MDP) ke tapak pelupusan.

Secara umumnya, pengurusan sisa pepejal yang cekap dan berjaya harus melibatkan semua warga sekolah. Tetapi sekolah dan alam sekitar yang kurang bersih berkemungkinan disebabkan oleh faktor penglibatan dan kesedaran yang kurang dalam diri setiap pelajar. Menurut Robinson (1996), pelajar sekolah mempunyai latar belakang, etnik, agama, jantina, tahap pendidikan yang berbeza. Maka, ciri peribadi seperti motivasi, pengetahuan dan penglibatan dalam pelbagai program kitar semula di sekolah juga berbeza. Namun, pelajar sekolah sering berinteraksi dan berhubung dalam aktiviti kehidupan mereka dan mengikuti tahap pendidikan yang sama di sekolah 
telah menimbulkan kesatuan antara mereka (Masyitah et al., 2011). Kesatuan ini menghasilkan nilai bertanggungjawab dan kerjasama secara bersepadu untuk menjayakan semua program kitar semula (Norpishah et al., 2017). Penglibatan pelajar boleh dalam bentuk sumbangan tenaga, barangan, kepakaran dan wang ringgit. Oleh itu, pelbagai program kitar semula dan sukatan baru Geografi telah diperkenalkan oleh Kementerian Pendidikan Malaysia (KPM) pada tahun 2019 untuk memupuk budaya kitar semula dalam diri pelajar. Ini kerana pelajar adalah golongan yang berpengetahuan yang boleh mengubah amalan kitar semula pada masa hadapan (Alias et al., 2014).

Oleh itu, pendidikan merupakan kunci utama untuk meningkatkan pengetahuan, penglibatan dan kesedaran pelajar terhadap isu-isu alam sekitar termasuklah amalan kitar semula (Hanifah et al., 2014). Penekanan kurikulum kitar semula dalam pendidikan adalah kepada penggunaan sumber alam dengan bijak khususnya dalam konteks perancangan, komitmen dan penglibatan dengan mengintegrasikan isu sosial, ekonomi dan alam sekitar (Nurul Hidayah, 2016). Penglibatan kanakkanak dalam usaha menerapkan pendidikan pengurusan sisa pepejal dan alam sekitar sememangnya diakui di peringkat antarabangsa (Hanifah et al., 2017). Ini disokong oleh Kahriman Ozturk et al. (2012) yang menyatakan bahawa di peringkat usia ini merupakan fasa terbaik dalam membangunkan personaliti kanak-kanak termasuk penglibatan, kesedaran dan penerapan nilai murni tentang amalan kitar semula. Justeru, kurikulum berkaitan kitar semula diajar dalam topik mata pelajaran Geografi tingkatan tiga (Ahmad Ridzuan et al., 2018).

\section{Metodologi Kajian}

Kajian ini telah menggunakan pendekatan kuantitatif dan kualitatif di sebuah sekolah menengah di daerah Penampang. Antara kaedah pengumpulan data yang digunakan adalah dengan menggunakan instrumen iaitu borang soal selidik (Noraini Idris, 2010). Dapatan kajian dianalisis dengan menggunakan SPSS, Versi 26. (Othman Lebar, 2014). Kajian ini merupakan kajian yang berbentuk bukan eksperimental di mana reka bentuk tinjauan telah dipilih (Chua, 2005). Kajian ini meninjau sejauh manakah pengetahuan pelajar terhadap penglibatan dan kesedaran dalam program kitar semula di sekolah. Disebabkan masalah jangkitan virus Covid 19 di negara kita menyebabkan kajian ini terpaksa ditukar dari soal selidik kepada pengisian Google Form. Pengunaannya merupakan satu instrumen yang menggunakan prosedur yang mudah dan cepat, kos pengurusan yang rendah, mesra alam dan kurang tekanan semasa menjawabnya. Tatacara dan prosedur yang sama telah digunakan dalam kajian ini iaitu mendapat kelulusan daripada pengetua sekolah. Segala kebenaran dan kelulusan telah dibuat dengan menggunakan alat teknologi dan multimedia iaitu melalui kemudahan telefon dan komputer.

Menurut Suzana dan Fariza (2014), penggunaan Google Form dapat menarik minat dan merangsangkan minda pelajar. Ia tidak melibatkan pergerakan yang banyak dan menjimatkan masa, tenaga dan kewangan (Muhammad Rizal, 2014). Selain itu, analisis dapatan boleh diperolehi dengan cepat dan mudah. Analisis excel dalam Google Form boleh dipindahkan terus ke dalam SPSS untuk digeneralisasikan kepada dapatan yang diperlukan mengikut objektif kajian. Pelajar juga kurang tekanan semasa menjawab Google Form kerana tiada limit masa diberikan untuk menjawabnya (Chua, 2006). Walaupun penggunaan Google Form mudah dan cepat tetapi terdapat beberapa halangan. Antaranya capaian internet terhad, kurang pengetahuan, sikap sambil lewa dan sebagainya telah mengganggu pengumpulan data (Norazilawati, 2013). 
Tambahan pula, pemerhatian ke atas tingkah laku dan penglibatan pelajar sekolah terhadap program dan amalan kitar semula di sekolah juga diteliti. Pemerhatian ikut serta dilakukan oleh penyelidik pada setiap hari persekolahan selama seminggu di sekolah kajian. Masa pemerhatian boleh dilakukan secara bebas yang pentingnya ia tidak mengganggu pengajaran dan pembelajaran guru dan pelajar dalam kelas. Jadi, penyelidik begerak dari satu blok ke satu blok bangunan sekolah, kantin, dewan dan pondok rehat pelajar untuk memantau tingkah laku dan sikap pelajar dalam amalan program kitar semula. Manakala pengurusan sisa pepejal dipantau melalui pekerja pembersih sekolah. Pemerhatian ke atas kesedaran dan penglibatan pelajar juga dibuat ke atas pengasingan sisa pepejal dalam tong kitar semula tiga warna. Pihak sekolah ada menyediakan tong sampah tiga warna di sudut lokasi yang strategik dalam kawasan sekolah untuk memudahkan pelajar membuang sampah mengikut jenisnya.

\section{Hasil kajian dan perbincangan}

Keputusan ujian statistik deskriptif telah dijalankan ke atas pemboleh ubah pengetahuan pelajar mendapati tahap pengetahuan pelajar sekolah berada pada tahap yang tinggi dengan min 3.7593 dan sisihan piawai 0.63383 . Didapati bilangan dan pengetahuan pelajar berkaitan dengan jumlah penghasilan sampah yang dihasilkan di sekolah pada setiap hari. Dalam erti kata lain, semakin ramai pelajar sekolah maka semakin banyak sampah yang dihasilkan oleh para pelajar sekolah tersebut. Data terbaru daripada Muhammad Yusri dalam Berita Harian Online pada 5 Oktober 2020 melaporkan, berdasarkan angka yang dikeluarkan oleh SWCorp, seorang rakyat dianggar menghasilkan $1.17 \mathrm{~kg}$ sampah sehari pada tahun 2018 berbanding 0.8kg (2005). Penghasilan sampah harian dalam kalangan rakyat di negara ini telah mencatat peningkatan $100.75 \%$ kepada 38,142 tan pada tahun 2018 berbanding 19,000 tan pada 2005.

Dapatan kajian tentang tahap penglibatan pelajar terhadap program kitar semula dilaporkan berada pada tahap yang sederhana dengan min sebanyak 3.5457 dan sisihan piawai 0.62411. Penglibatan pada tahap sederhana ini sudah pasti dan masih boleh dipertingkatkan lagi agar program kitar semula berjaya sepenuhnya dilaksanakan di sekolah. Menurut Alias et al. (2014), pendedahan dan kemudahan program kitar semula yang efektif dan sistematik dapat menggalakkan penglibatan pelajar dalam pengamalan kitar semula dengan adanya sokongan daripada semua pihak. walaupun dapatan jelas menunjukkan terdapat penglibatan dalam program kitar semula di sekolah tetapi tidak semua pelajar melakukannya. Setiap individu pelajar atas kapasiti kesedaran menyebabkan ada segelintir pelajar yang tidak mengamalkan kitar semula dalam kehidupan seharian. Secara purata seramai 284 pelajar (88.75\%) didapati dan mengakui mereka tidak mengasingkan sisa buangan dan mengamalkan amalan kitar semula. Ini kerana pelajar malas melakukannya dan menggangap perkara ini tidak memberikan apa-apa kepentingan dan faedah kepada diri. Mereka tahu tentang program kitar semula tetapi tidak mahu mempraktikkannya menyebabkan sisa pepejal semakin bertambah di tapak pelupusan sampah di seluruh Malaysia (Abdul Hair, 2016).

Selain itu, tahap kesedaran pelajar terhadap program kitar semula pula berada pada tahap yang sederhana (Min 3.3243 dan Sisihan Piawai 0.60419). Analisis kajian merumuskan bahawa tahap kesedaran pelajar sederhana di sekolah tetapi tidak menjamin pelajar ini akan melakukan program kitar semula dengan baik mengikut warna tong kitar semula. Pengetahuan kitar semula dan pelaksanaan program kitar semula di sekolah bertujuan untuk membentuk warga pelajar yang lebih mengambil berat terhadap isu pengurusan sisa pepejal. Oleh itu, penegasan perlu diberikan oleh pihak sekolah kepada pengetahuan, penglibatan dan kesedaran di kalangan pelajar sekolah 
untuk memastikan pengurusan sisa pepejal yang lebih sistematik. Justeru, pendidikan adalah medium terpenting untuk memperbaiki keupayaan dan penglibatan pelajar dalam pelaksanaan pelbagai program kitar semula dan. Amalan kitar semula dan alam sekitar perlu dijadikan perkara yang utama dalam kehidupan pelajar supaya amalan ini dapat mengurangkan jumlah sisa (Noor Cheku et al., 2014; Augustine, 2017). Noor et al. (2014) dan Ezanee et al. (2016) juga menjelaskan pengetahuan mengenai kitar semula dapat mengubah sikap dan amalan seseorang. Jadual 1 menunjukkan tahap pencapaian pengetahuan pelajar terhadap topik kitar semula bagi mata pelajaran Geografi tingakatan empat di sekolah menengah Datuk Peter Mojuntin.

Jadual 1. Tahap pengetahuan pelajar dalam topik kitar semula

\begin{tabular}{lccc} 
Tahap Pengetahuan Pelajar & Gred & Kekerapan & Peratus (\%) \\
\hline Tinggi (skor $85 \%-100 \%$ ) & A-B & 173 & 54.05 \\
\hline Sederhana (skor 65\% - 84\%) & C-D & 54 & 16.30 \\
\hline Rendah (Skor 40\% - 65\%) & E-F & 47 & 14.65 \\
\hline Gagal (skor kurang 39\%) & G & 48 & 15.00 \\
\hline
\end{tabular}

Seramai 173 pelajar sekolah mencapai tahap pengetahuan yang tinggi dengan peratus 54.05\%. Walaupun begitu, sebanyak 48 pelajar (15\%) pelajar gagal dalam topik kitar semula dan $30.95 \%$ pelajar mempunyai pengetahuan yang sederhana. Pengetahuan yang sederhana dan rendah terhadap topik ini harus ditingkatkan menerusi pengajaran guru Geografi dan penglibatan pelajar dalam pelbagai program kitar semula. Selain itu, sumbangan kewangan daripada sektor swasta juga penting untuk menggalakkan penyertaan pelajar dalam menjayakan program ini. Menurut Hanifah et al. (2014) pengetahuan dan keupayaan mental pelajar dapat membantu seseorang untuk melaksanakan tanggungjawab dengan baik khususnya pengetahuan pelaksanaan program kitar semula. Guru yang berprofesional dapat menyampaikan pengetahuan yang menyeronokkan dengan memberikan kebebasan kepada pelajar untuk menghasilkan projek kitar semula mengikut kreadiviti masing-masing.

Tambahan pula melalui penemuan kajian oleh Hanifah et al. (2017) dan Ezanee et al. (2016) juga membuktikan bahawa pengetahuan yang dimiliki oleh pelajar dapat mengubah kelakukan dan sikap pelajar dengan tahap pengetahuan pelajar universiti sangat tinggi dalam pengasingan tong kitar semula. Pendidikan kitar semula dapat membantu pelajar sekolah untuk menyedari dan memahami isu kitar semula dan dapat menguasai kemahiran pengurusan sisa pepejal serta kesungguhan mengatasi serta mengekalkan kualiti alam sekitar (Norpishah, 2017). Pengetahuan yang dipelajari melalui sistem pendidikan Malaysia khususnya dalam topik kitar semula dalam mata pelajaran Geografi selalu tidak dijadikan teladan dalam kehidupan seharian pelajar. Tahap pengetahuan yang tinggi tidak semestinya dipraktikkan dalam program kitar semula dan pengurusan sisa pepejal yang ada di sekolah pada masa sekarang menyebabkan masalah pembuangan sisa pepejal tidak dapat diatasi (Seow, 2009).

Semua sisa pepejal sekolah di daerah Penampang telah ditender kepada sebuah syarikat swasta yang bernama Alyssa Enterprise Sendirian Berhad di mana mereka telah mengupah empat kontraktor pembersih dan seorang tukang kebun untuk mengurus sisa pepejal sekolah. Ketua kontraktor membahagikan kawasan sekolah kepada beberapa zon yang digelar Blok A, Blok B, Blok C dan Block D. Blok A meliputi kawasan depan padang sekolah dan pentadbiran, blok B dan $\mathrm{C}$ adalah bangunan kelas tingkatan tiga dan empat serta lima, blok D pula meliputi makmal komputer hingga kawasan sekitar dewan harmoni serta kantin sekolah. Manakala tugas tukang kebun lebih kepada landskap dan kecantikan kawasan alam sekitar sekolah. Seorang ketua 
kontraktor dilantik antara mereka untuk membahagikan tugas kepada rakan bawahannya. Pekerja boleh mengetahui tugas dan pemungutan serta jagaan tong sampah masing-masing di lokasi yang ditetapkan. Jumlah kekerapan pemungutan sampah adalah tiga kali sehari iaitu selepas pelajar rehat dan kerja tersebut harus diselesaikan sebelum mereka pulang. Pekerja ini bertanggungjawab mengutip dan memindahkan semua sampah daripada tong sampah bewarna hitam atau hijau ke dalam plastik hitam yang besaiz ukuran 40 x 45 dengan jumlah kira-kira 18 hingga 20 plastik sampah pada setiap hari persekolahan. Jumlah kos yang dianggarkan untuk mengupah pekerja pembersih dan bekalan plastik hitam serta peralatan yang lain adalah kira-kira sebanyak RM 85,000 setahun bagi sebuah sekolah menengah. Lori pemungut dari Majlis Daerah Penampang (MDP) akan memungut semua sisa pepejal sekolah seminggu sekali iaitu pada malam jumaat atau pagi hari sabtu. Dengan pemungutan sehari dalam seminggu telah menyebabkan pencemaran udara dan berbau busuk (Nurul Hidayah, 2016).

Selain itu, amalan konsep 3R juga diterapkan dalam pengajaran guru dan program kitar semula di sekolah ini. Ini bertujuan untuk meminiumkan penggunaan kertas di yang banyak dijana (Hasnah et al., 2011). Jadual 2 menunjukkan tahap amalan pelajar terhadap konsep 3R di sekolah. Didapati bahawa 248 (77.5\%) pelajar mempunyai tahap amalan 3R yang sederhana, diikuti oleh 48 pelajar (19.35\%) pada tahap rendah dan hanya 24 pelajar $(7.5 \%)$ sahaja tahap tinggi dalam amalan konsep 3R di sekolah ini.

Jadual 2. Tahap amalan konsep $3 \mathrm{R}$ dalam program kitar semula di sekolah

\begin{tabular}{lcc}
\hline Tahap Amalan & Kekerapan & Peratus (\%) \\
\hline Tinggi (Skor melebihi 24) & 24 & $7.5 \%$ \\
Sederhana (Skor di antara 18-24) & 248 & $77.5 \%$ \\
Rendah (Skor kurang daripada 18) & 48 & $19.35 \%$ \\
\hline
\end{tabular}

Manakala ujian korelasi (Pearson Product-Moment) digunakan bagi menganalisis hubungan antara dua pemboleh ubah kajian iaitu untuk mengenal pasti sejauh manakah hubungan antara pengetahuan, penglibatan dan kesedaran pelajar terhadap pelbagai program kitar semula di sekolah menengah Datuk Peter Mojuntin, Penampang. Antara progam yang diadakan iaitu program sekolah lestari, program persatuan Tzu Chi, program gotong-royong perdana, program pertandingan kitar semula dan sebagainya yang diadakah pada setiap tahun di sekolah. Penganjuran pelbagai program kitar semula ini adalah bertujuan untuk menggalakkan dan memberi peluang kepada para pelajar sekolah menyertai dan melibatkan diri secara langsung dalam program ini. Dengan penglibatan ini, pelajar dapat mengamalkan amalan kitar semula dan mempratikkan dalam pembuangan sisa pepeja di sekolah dengan mengasingkan sampah mengikut warna tong kitar semula.

Jadual 3. Analisis statistik korelasi pearson

\begin{tabular}{llcc} 
& & Pengetahuan & Kesedaran \\
\hline Pengetahuan & Pearson Correlation & 1 & $.712^{* *}$ \\
& Sig. (2-tailed) & & .000 \\
& $\mathrm{~N}$ & 320 & 320 \\
\hline Kesedaran & Pearson Correlation & $.712^{* *}$ & 1 \\
& Sig. (2-tailed) & .000 & 320 \\
& $\mathrm{~N}$ & 320 & \\
\hline
\end{tabular}


Jadual 3 menunjukkan nilai pekali korelasi antara pemboleh ubah pengetahuan dan penglibatan pelajar dalam program kitar semula, $r=0.712$. Aras kesignifikan yang sebenar $=0.001$ (sangat signifikan). Sebanyak 320 pasang skor digunakan untuk mendapatkan pekali kolerasi antara pemboleh ubah pengetahuan dan penglibatan pelajar terhadap program kitar semula di sekolah, $(\mathrm{N}=320)$. Dapatan menunjukkan hasil analisis korelasi antara pemboleh ubah yang terlibat, interprestasi hubungan berdasarkan Bond dan Fox (2007) menyatakan hubungan bagi pemboleh ubah terlibat merupakan satu hubungan tinggi ke sangat tinggi yang sangat signifikan, (r) $320=0.712, \mathrm{k}<.05$. Keputusan korelasi yang signifikan ini mengesahkan bahawa apabila skor min pengetahuan pelajar adalah tinggi, maka skor min penglibatan pelajar dalam program kitar semula juga dilaporkan tinggi.

Jadual 4. Analisis Statistik Korelasi Pearson

\begin{tabular}{llcc} 
& & Pengetahuan & Kesedaran \\
\hline Pengetahuan & Pearson Correlation & 1 & $.788^{* *}$ \\
& Sig. (2-tailed) & & .000 \\
& $\mathrm{~N}$ & 320 & 320 \\
\hline Kesedaran & Pearson Correlation & $.788^{* *}$ & 1 \\
& Sig. (2-tailed) & .000 & 320 \\
\hline
\end{tabular}

Jadual 4 menunjukkan nilai pekali korelasi antara pemboleh ubah pengetahuan dan kesedaran pelajar terhadap program kitar semula di sekolah, $r=0.788$. Aras kesignifikan yang sebenar $=0.001$ (sangat signifikan). Sebanyak 320 pasang skor digunakan untuk mendapatkan pekali korelasi antara pemboleh ubah pengetahuan dan kesedaran pelajar, $\mathrm{N}=320$. Dapatan menunjukkan bahawa hasil analisis korelasi antara pengetahuan dan kesedaran pelajar diinterpretasi hubungan berdasarkan Bond dan Fox (2007) menyatakan hubungan bagi pemboleh ubah terlibat merupakan hubungan tinggi ke sangat tinggi yang sangat signifikan, $\mathrm{r}(320)=0.788$, $\mathrm{K}<.05$. Keputusan korelasi yang signifikan ini mengesahkan bahawa apabila skor min pengetahuan itu tinggi, maka skor min kesedaran pelajar juga dilaporkan tinggi. Keputusan adalah selari dan juga menandakan jika pelajar mempunyai pengetahuan tentang program kitar semula dan alam kitar yang tinggi tentu dapat melahirkan pelajar yang ada amalan kitar semula yang baik di sekolah. Selain itu, jika cara dan teknik pengajaran guru adalah cemerlang, maka skor pengetahuan pelajar juga dilaporkan tinggi. Dengan adanya pengetahuan dalam diri setiap pelajar tentu dapat melahirkan dan memupuk budaya kitar semula di sekolah yang seterusnya dapat memastikan pengurusan sisa pepejal secara terkawal dan terancang.

Justeru, program kitar semula yang dilaksanakan di sekolah dapat memberikan banyak faedah dan kepentingan kepada para pelajar. Pelajar sedar kepentingan program kitar semula seperti mengurangkan pencemaran alam sekitar, menambahkan pendapatan dan memupuk sikap jimat-cermat dalam menggunakan bahan kitar semula (Siti Khatijah dan Christopher, 2016). Pendedahan dan penglibatan setiap warga sekolah ke atas pelbagai program kitar semula adalah amat penting kerana ia boleh menjaga kebersihan sekolah dan alam sekitar. Berdasarkan analisis data kajian didapati $23.75 \%$ pelajar terlibat secara langsung dalam memberi penjelasan, pengetahuan dan amalan mengendalikan program kitar semula sekolah. Golongan pelajar ini sangat aktif fan melibatkan diri secara langsung dalam semua program kitar semula sekolah. Kenyataan ini turut disokong oleh Noor Cheku et al. (2014), penglibatan semua pelajar sekolah seperti mencipta, merancang dan melaksana pelbagai program kitar semula yang meliputi 
beberapa dimensi dapat menggalakkan penglibatan secara sukarela pelajar dalam program ini. Antara program yang menjadi fokus dan utama di sekolah ini pada masa sekarang adalah program persatuan Tzu Chi.

Persatuan Tzu Chi adalah sebuah badan sukarela yang ditubuhkan oleh sektor swasta untuk membantu masyarakat dan pihak sekolah. Pegawai persatuan Tzu Chi telah mengadakan bantuan dan sumbangan mereka di semua sekolah menengah di daerah Penampang dari segi tenaga kerja, pendidikan dan pengetahuan, kebajikan dan bantuan derma. Mereka telah membantu pelajar miskin dan memberi biasiswa kepada pelajar yang tinggal di kawasan yang jauh dari sekolah. Selain itu, Persatuan Tzu Chi juga tidak terkecuali menjadikan 3R ini sebagai satu peluang untuk menambahkan pendapatan kebajikan kepada pelajar. Oleh yang demikian, beberapa langkah telah diambil untuk memperluaskan pasaran amalan 3R ini di sekolah. Mereka juga mengadakan pelbagai aktiviti promosi yang dijalankan untuk menarik minat warga sekolah agar menjadikan kitar semula sebagai satu aktiviti yang mampu untuk menjana pendapatan kepada pihak sekolah seperti menjual hasil barang kitar semula, kad tema hari guru dan sebagainya (Kho et al., 2017).

Dalam konteks penglibatan pelajar dalam persatuan Tzu Chi di sekolah tentang barangan yang boleh dikitar semula, pelajar kelab pencintai alam sekolah telah membantu persatuan Tzu Chi untuk mengasingkan sisa pepejal sekolah untuk dijual kepada pengusaha kitar semula yang menjalankan aktiviti pembelian dan pemungutan di sekolah seperti GNG Recyle Sdn Bhd yang sangat aktif dalam pembelian bahan kitar semula. Dapatan kajian daripada pemerhatian menunjukkan bahawa terdapat lima jenis barangan kitar semula yang dikumpul dan dijual iaitu tin aluminium, kertas terpakai, bahan plastik, botol mineral, botol kaca, kadbod dan sebagainya. Jadual 5 dan 6 menunjukkan pendapatan yang diperolehi daripada penjualan bahan kitar semula di sekolah kajian bagi tahun 2019 adalah sebanyak 3202.50kg (RM631.85) dan 2020 tidak dapat ditentukan kerana masalah Covid.

Jadual 5. Jumlah dan hasil jualan bahan kitar semula sekolah bagi tahun 2019

\begin{tabular}{clcc}
\hline Bil & Tarikh kutipan & Jumlah Berat (KG) & Jumlah Hasil Jualan (RM) \\
\hline 1. & $01-02-2019$ & 922 & 144.05 \\
2. & $21-01-2019$ & 255 & 60.95 \\
3. & $21-03-2019$ & 156 & 40.30 \\
4. & $10-04-2019$ & 113 & 32.25 \\
5. & $08-05-2019$ & 241 & 54.35 \\
6. & $24-05-2019$ & 67 & 12.75 \\
7. & $04-07-2019$ & 216 & 51.75 \\
8. & $02-08-2019$ & 259 & 48.70 \\
9. & $26-08-2019$ & 112 & 26.35 \\
10. & $25-09-2019$ & 136 & 34.65 \\
11. & $18-10-2019$ & 242 & 44.45 \\
12. & $07-11-2019$ & 131.5 & 28.35 \\
13. & $25-11-2019$ & 352 & 52.95 \\
\hline
\end{tabular}

Jadual 6. Hasil jualan bahan kitar semula SMK DPM bagi tahun 2020

\begin{tabular}{ccc}
\hline Tarikh & Perkara & Wang masuk \\
\hline 7.1 .2020 & Hasil penjualan bahan kitar semula & 43.24 \\
11.2 .2020 & Hasil penjualan bahan kitar semula & 55.60 \\
25.2 .2020 & Hasil penjualan bahan kitar semula & 115.25 \\
\hline
\end{tabular}


Program Tzu Chi di sekolah telah mencapai matlamat mereka iaitu mendidik pelajar sekolah mengendalikan program kitar semula melalui kelab pencintai alam sekolah. Mereka juga menghulurkan bantuan kewangan kepada golongan pelajar yang miskin dari segi tambang bas dan biasiswa. Penglibatan sebagai badan sukarelawan mengutip dan membantu mengasingkan bahan kitar semula di sekolah dan kawasan sekitar telah diadakan di 22 pusat kitar semua di bandaraya Kota Kinabalu termasuklah tiga di daerah Penampang (Tan, 2014). Persatuan Tzu Chi menetapkan hari Jumaat pada minggu terakhir dalam sebulan untuk mengumpul bahan kitar semula di sekolah ini. Mereka mengamalkan aktiviti kitar semula secara menyeluruh tanpa merasakan bahan kitar semula di sekolah adalah sesuatu yang kotor dan berbau busuk. Ini terlihat semasa pemerhatian di sekolah dengan kesungguhan mereka dalam bekerja tanpa mengenal penat dan lelah walaupun kitar semula tersebut sesuatu yang agak membebankan. Kesungguhan dan kerajinan yang ditunjukkan telah menarik perhatian dan motivasi pelajar sekolah untuk sama-sama membantu menjayakan program kitar semula sekolah dengan jumlah ahlinya seramai 85 pelajar pada tahun 2020 ini. Angka ini pasti akan bertambah pada tahun hadapan memandangkan pihak sekolah akan mempromosikan program ini dan memberikan merit kepada pelajar yang menyertainya.

Hujah juga disokong oleh dapatan kajian Alias et al. (2014) yang menjelaskan penglibatan dan kerjasama daripada semua warga sekolah dan PBT dapat mengurangkan jumlah sisa yang dihantar ke tapak pelupusan dengan pengamalan kitar semula. Kesanggupan setiap individu untuk terlibat dalam aktiviti asingkan sampah ke tong sampah tiga warna juga membawa nilai dan pendapatan tambahan untuk semua bahan kitar semula (Mapa, 2017; Mapa et al. 2019). Pihak sekolah perlu memandang serius akan hal ini kerana pengurusan program kitar semula yang baik memerlukan penglibatan semua pelajar sekolah (Siti Khatijah dan Christopher, 2016). Reka bentuk program memainkan peranan penting dalam menarik minat pelajar untuk terlibat dalam program kitar semula kerana jika diamati program yang diadakan masih kurang mendapat sambutan walaupun telah banyak kali dilancarkan oleh pihak sekolah setiap tahun. Kajian Hanifah et al. (2014) dan Murugan (2019) mendapati bahawa tiada perkaitan yang jelas antara penglibatan dan kesedaran pelajar dengan program kitar semula jika sikap dan tabiat pelajar tidak ubah secara semula jadi.

Walaupun penglibatan yang aktif tetapi hanya sebahagian kecil daripada pelajar sekolah yang menyedari dan mengetahui kepentingan pelaksanaan program kitar semula ini di sekolah. Ini jelas dilihat daripada cara pembuangan sampah di dalam kelas, pelajar suka membuang sampahnya di sekeliling tong sampah dan mengganggap tong sampah sebagai tempat menjaringkan gol untuk bola. Melihat kepada senario ini, pihak sekolah, kerajaan dan swasta perlu mengadakan pelbagai program yang mampu meningkatkan pengetahuan dan kefahaman pelajar selain memberikan kemahiran kepada pelajar mengenai pengurusan sisa pepejal (Murugan, 2019). Analisis juga membuktikan pihak sekolah dan pihak luar masih mampu meningkatkan tahap keterlibatan semua warga sekolah dalam pelbagai program memandangkan kelas masih kotor (Zaini et al., 2017). Tabiat pelajar akan berubah dengan adanya motivasi, minat dan galakkan (Augustine, 2017). Justeru, semua warga sekolah haruslah berganding bahu dalam menjayakan program kitar semula melalui pengetahuan yang diperolehi dan pengalaman yang didapati sebelum ini.

\section{Kesimpulan}

Penglibatan dan kesedaran pelajar merupakan tiga pemboleh ubah yang sangat penting dan berkesan untuk meningkatkan amalan kitar semula dan pengurusan sia pepejal dalam kalangan 
warga sekolah. Dengan pelaksanaan pelbagai program kitar semula dan pengurusan sisa pepejal yang sistematik di sekolah pastinya dapat memanjangkan jangka hayat tapak pelupusan. Pengurusan sisa pepejal yang baik adalah sangat penting untuk mencapai sekolah bersih dan sifar sampah. Walau bagaimanapun, untuk mencapai semua matlamat yang telah dhasratkan masih memerlukan kerjasama daripada semua pihak yang terlibat secara langsung dalam kehidupan pelajar. Antara termasuklah pengetua, guru, ibu bapa dan pelajar. Sebagai pemimpin tertinggi dalam sekolah, pengetua memainkan peranan yang penting untuk memastikan sesuatu program dan pengurusan yang dilaksanakan berjaya mencapai objektif yang telah ditetapkan. Guru sebagai agen penyampai pengetahuan sememangnya tidak dapat dinafikan fungsinya dalam melahirkan kemenjadian pelajar terutamanya dalam aspek akademik, kokurikulum dan sahsiah. Manakala ibu bapa sebagai model ikutan di rumah juga menyumbangkan usahanya untuk memastikan generasi baharu dididik dengan sahsiah yang positif. Pelajar sebagai kumpulan sasaran diharapkan dapat menerima pengetahuan dan didikan daripada semua pihak untuk memastikan penglibatan dan kesedaran terhadap program kitar semula dapat dicapai ke tahap yang maksimum.

\section{Rujukan}

Abdul Hair Beddu Asis. (2016). Pengurusan tapak pelupusan mapan melalui pendekatan kitar semula di Sabah. (Tesis Doktor Falsafah), Fakulti Kemanusiaan, Seni dan Warisan. Universiti Malaysia Sabah: Kota Kinabalu.

Ahmad Ridzuan, A. R., Rajini, G. \& Pau, U. (2018). Buku teks Geografi tingkatan 3. Kementerian Pendidikan Malaysia: IMS Books Trading Sdn Bhd.

Agamuthu, P., Fauziah, S. H. \& Khidzir, K. (2009). Evolution of solid waste management in Malaysia: Imparts and implications of the solid waste bill 2007. Journal of Matter Cycles Waste Management, 11, 96-103.

Agamuthu, P. \& Tarmudi, S. H. (2012). Challenges and issues in moving towards sustainable landfilling in a transitory country - Malaysia. Waste Management and Research, 29, 13-19.

Alias, F.S., Manaf, L.A., Ho, M., Onn, N., \& Abdullah, S.J.H. (2014). Knowledge and attitude of water villagers towards solid waste management. British Journal of Arts and Social Sciences, $16(2), 88-100$.

Augustine, T. (2017). Penjagaan Alam Sekitar: Cabaran dan Pengurusan Domestik. Dipetik dari www.malaysian-ghost-research-org/pengurusan-sisa-pepejal-domestik/Htm

Bond, T. \& Fox, C. (2007). Applying the Rasch Model: Fundamental measurement in the human sciences (2nd). Mahwah, NJ: LEA.

Chua, Y. P. (2005). Kaedah dan Statistik Penyelidikan. Kuala Lumpur: McGraw-Hill Malaysia Sdn. Bhd.

Chua, Y. P. (2006). Kaedah Penyelidikan, Buku 1. Kuala Lumpur: McGraw-Hill Malaysia Sdn. Bhd.

Ezanee, M. E., Zakirah, O., Norlida, M., Mohd, N. M. N., Santhirasegaran, S. \& Nadarajan, R. (2016). Program kitar semula: Persepsi masyarakat terhadap ReDMac. Sains Humanika, $8(4), 1-7$.

Habib, K., Schmidt, J, H. \& Christense, P. (2013). A historical perspective of global warning potential from municipal solid waste management. Waste Management. 33, 1926-1933. 
Hanifah, M., Mohmadisa, H., Yazid, S., Nasir, N. \& Safyidatina, B. N. (2017). Pengetahuan dan amalan hijau dalam kalangan murid sekolah rendah. Jurnal Pendidikan Malaysia, 42(1), 4149.

Hanifah, M., Shaharrudin, A., Mohamad Suhaily, Y., C., N., \& Noraiziah, A. (2014). Pendidik pembangunan lestari - Hubungan kesedaran antara ibu bapa dengan pelajar. GeografiaMalaysian Journal of Society and Space, 10(5), 71-84.

Hasnah, A., Dody, D., Noraziah, A., Maznah, I., \& Sarifah, Y. (2012). Masyarakat dan amalan pengurusan sisa pepejal ke arah kelestarian komuniti: Kes isi rumah wanita di bandar baru Bangi, Malaysia. Geografia-Malaysian Journal of Society and Space, 8(5), 64-75.

Kementerian Pendidikan Malaysia. (2017). Kurikulum standard sekolah menengah. Bahagaian Pembangunan Kurikulum.

Kahriman, O, D., Olgan, R., \& Tuncer, G. (2012). A qualitative study on Turkish preschool children environmental attitudes through ecocentrism and anthropocentrism. International Journal of Science Education, 34(4), 629-650.

Kho, S. H., Wong, J. X., Saravanan, S. S. \& Mohamad. T. M. (2017). Peranan NGO dalam pengurusan sisa pepejal: Kajian kes kegiatan kitar semula oleh Persatuan Tzu Chi di Kota Kinabalu, Sabah. Bahagian geografi. Prosiding Persidangan Kebangsaan Masyarakat, Ruang dan Alam Sekitar. 23-24 Februari, 2017. Universiti Sains Malaysia, Pulau Pinang.

Mapa, M. T., Haris, L. M., George, F., Dinggai, M.s., Japar, A., \& Gulasan, A. (2019). Kajian komposisi dan pengasingan sisa pepejal di kawasan perumahan. Geografia-Malaysian Journal of Society and Space, 15(2), 117-1280. Http://doi.org/10.17576/geo-2019-1502-09

Masyitah, M. N., Nurjuhanah, J., \& Juliana, M. (2011). Kajian penjanaan sisa pepejal dan tahap kesedaran penduduk terhadap kitar semula di seluruh negeri Perlis. Jurnal Intelek, 6(1), 123131.

Muhammad Rizal Fauzi. (2014). Penggunaan Google form sebagai alat evolusi pembelajaran mata pelajaran Bahasa Indonesia: Studi deskriptif analitis pada kelas viii di sekolah menengah Pertama, Negeri 1 Lembang. Tesis Universitas Pendidikan Indonesia.

Muhammad Yusri Muzamir. (2020). Berita Harian Online, 5 Okt 2020. https://www.bharian.com.my/berita/nasional/2020/01/643354/pembuangan-sam

Murugan, M, R., (2019). Pengetahuan dan amalan kitar semula oleh guru pelatih institut pendidikan guru. Jurnal penyelidikan IPGK, 16, 1-16

Noor, Cheku., H, Ibrahim, M., \& Mohd Yusri, I. (2014). Hubungan sikap alam sekitar dan amalan kitar semula di negeri Terengganu. Social Sciences Postgraduate International Seminar (SSPIS), Pusat Pembangunan Sosioekonomi dan Pusat Pendidikan Ass dan Liberal, Universiti Malaysia Terengganu. PP, 137-147. ISBN9789671147313.

Noraini Idris. (2010). Penyelidikan dalam pendidikan. Kuala Lumpur: McGraw-Hill Malaysia Sdn. Bhd.

Norazilawati, A. (2013). Aplikasi persekitaran pengajaran Maya (Frog Vle) dalam kalangan guru Sains. Jurnal Pendidikan Sains dan Matematik Malaysia, 3(2), 2232-0393.

Norpishah, A., Rosnani, A., \& Rozimah, T. (2017). Kitar semula sisa pepejal di Politeknik Sultan Salahuddin Abdul Aziz Shah. Advanced Journal and Vocational Education, 1(1), 161-167.

Ng, L, S. (2015). Pelaksanaan dasar pengurusan sisa pepejal negara dalam kalangan kontraktor industri pembinaan di Pulau Pinang. (Tesis Sarjana). Fakulti Pengurasan Teknologi dan Perniagaan, Universiti Tun Hussien Onn Malaysia.

Nurul Hidayah, L, A., Haryati, S., \& Seow, T. W. (2016). Pendidikan alam sekitar sebagai medium utama dalam konteks meningkatkan kesedaran alam aekitar: Satu tinjauan persepsi dari 
sudut pandangan pentadbir, guru, ibubapa dan murid. Prosiding Seminar Antarabangsa ke6 Ekologi, Habitat Manusia dan Perubahan Persekitaran di Alam Melayu.

Othman Lebar, (2014). Penyelidikan Kualitatif. Universiti Pendidikan Sultan Idris, Tanjung Malim: Perak.

Perbadanan Pengurusan Sisa Pepejal dan Pembersihan Awam. (2019). Dipetik dari https://jpspn.kpkt.gov.my/index.php/pages/view/106

Robinson, J. G. (1996). Searching for the community in community-based conservation: A case study of a Zimbabwe campfire project. (Masters Thesis). Toronto: School of Environmental and Resource Studies, Dalhousie University.

Rosmidzatul, A, M, Y. (2015). Kitar Semula. Pegawai Penyelidik Kanan, Pusat Kajian Sains dan Alam sekitar, Institut Kefahaman Islam Malaysia.

Seow, T. W., Jamaluddin, Md. J., \& Indera Syahrul, M. R. (2004). Tingkah laku masyarakat terhadap program kitar semula: Kajian kes di Daerah Batu Pahat. KUiTTHO: Parit Raja.

Seow, T. W. (2004). Pengurusan sisa pepejal di Malaysia. Jurnal Sains Sosial, 2(1), 9-25.

Seow, T, W. (2009). Masalah pengurusan sisa pepejal di Daerah Batu pahat, Johor. (Tesis Doktor Falsafah). Fakulti Sains Sosial dan Kemanusiaan. Universiti Kebangsaan Malaysia: Bangi.

Siti Khatijah, Z., \& Noraziah, A. (2014). Komuniti bandar dan pengurusan sisa pepejal: Kajian kes di Bandaraya Kuching. Geogafia,-Malaysian Jounal of Society and Space, 10(6), 126-137.

Siti Khatijah, Z., \& Christopher, P. (2016). Cabaran dan strategi ke arah pembentukan komuniti lestari. Geogafia-Malaysian Jounal of Society and Space, 12(12), 10-24.

Suzana, S., \& Khaild, F. (2014). Pengajaran dan Pembelajaran Menggunakan Perisian GoogleSatu Analisis Kajian Lepas. Dalam F. Khalid (Ed.), Pengajaran Sumber dan Teknologi Maklumat: Impaknya ke atas Penyelidikan dalam Pendidikan (Vol. 1, pp. 25-32). Bangi: Fakulti Pendidikan, UKM.

Tan, J. E. (2014). Community Recycling: Taiwan Buddhist Tzu Chi foundation Malaysia. Lingking sustainable development with the social and solidarity economy (SSE). Dipetik dari https://sdg-sse.org/en/projects/community-recycling-taiwan-buddist-Tzu-chifoundation-malaysia/

Zaini, S. (2011). Municipal solid waste management in Malaysia: Solution for sustainable waste management. Journal of Applied Sciences in Environmental Sanitation, 6, 29-38.

Zaini, S, Sofia, A., \& Mohd Firdaus, S. (2017). Pengetahuan komuniti dan amalan pengurusan sisa pepejal di Negeri Sembilan. Geografia-Malaysian Journal of Society and Space, 13(4), 126137.

Zamri, M., \& Mohamed, A, E. (2008). Teknologi maklumat dan komunikasi dalam pengajaran dan pemelajaran Bahasa Melayu: Teori dan praktis. Shah Alam: Karisma Publications Sdn. Bhd. 